\title{
Sedentary Screen Time as a Coping Strategy of Distance Learning-induced Distress during COVID- 9 Pandemic
}

\author{
Ghea Mangkuliguna \\ School of Medicine and Health Sciences, \\ Atma Jaya Catholic University of Indonesia \\ ghea.201706000047@student.atmajaya.ac.id
}

Veronika M. Sidharta

Department of Histology, School of Medicine and Health Sciences,

Atma Jaya Catholic University of Indonesia veronika.maria@atmajaya.ac.id

\author{
Mahaputra \\ Department of Psychiatry, School of Medicine and \\ Health Sciences, \\ Atma Jaya Catholic University of Indonesia \\ mahaputra@atmajaya.ac.id
}

\begin{abstract}
During the COVID-19 pandemic, medical students might be vulnerable to excessive screen time exposure to cope with distance learning-induced distress. This study aimed to evaluate the distress and screen time before and after distance learning was initiated. Data were collected from 215 subjects. Statistical significance was accepted at $P<0.05$. The prevalence of distress among medical students was $25.61 \%$ and $27.06 \%$ before and after distance learning was executed, respectively. Academic-related stressor (ARS) was reported by $49.28 \%$ and $63.29 \%$ of students during the first and second surveys. The proportion of students with daily screen time $\geq 7$ hours was $51.21 \%$ and $63.77 \%$ for the first and second surveys, respectively. ARS, interpersonal and intrapersonal-related stressor (IRS), social-related stressor (SRS), and average daily screen time significantly rosein 3-month-time $(P<0.000 \mathrm{I}, P=0.00 \mathrm{I} 4, P=0.026 \mathrm{I}, P=0.0022)$. There was a significant association between distress and screen time $(P=0.03 / 3)$. ARS was the leading cause of distress. The majority of respondents had a daily screen time $\geq 7$ hours. Both distress and screen time levels significantly increased as distance learning kept progressing.
\end{abstract}

Keywords: COVID-19; distance learning; mental distress; medical students; screen time. 


\section{Introduction}

As of July 23, 2020, Coronavirus disease 2019 (COVID-19) has become a worldwide pandemic infecting more than 14.9 million people ("WHO”, 2020). It has brought a devastating impact on global health, accounting for more than 618.000 deaths across 216 countries in the world. In Indonesia, the battle against COVID-19 has started since early March, and the number of infected people keeps on rising each day, reaching more than 90.000 confirmed cases by this time ("Peta sebaran", 2020).

Currently, social distancing is actively being enforced to reduce the risk of transmission of this disease. This policy includes shutting down public places where many people are likely to gather, such as public schools. As a result, students' education has shifted from traditional 'in-person' lecture-based teaching to distance learning via online platforms (Rose, 2020).As online learning keeps on progressing, some students report that they struggled with loneliness, frustration, and boredom. They were also easily distracted and lost motivation to work (Venkatesh \& Edirappuli, 2020). This can potentially lead to psychological distress (Cao et al., 2020).

The prevalence of mental distress was already high among medical students and might impair the ability to perform well throughout their studies (Melaku et al., 20I5; Nivetha, et al., 2018; Yusoff, 2017). Moreover, medical students are categorized as young adults, which according to American Psychological Association (2012) showed the highest level of stress compared to other age group.It is reported that academic-related stressor was the primary source of stress among medical students (Melaku et al., 2015; Mudor \& Mudor, 20I5; Nivetha, Ahmed, \& Prashantha, 2018; Patil et al., 2017). Other potential causes of mental discomfort included interpersonal and intrapersonal-related stressors, teaching and learning-related stressors, social-related stressors, drive and desire-related stressors, and group activities-related stressors (Yusoff et al., 2010).

After confronted with stressful events or environments, some individuals might increase their screen time as a way to find salvation and get emotional support (Khalili-Mahani et al., 2019; Wang et al., 2015; Xu et al., 2019). However, excessive screen time has shown 
adverse effects on physical and emotional well-being, including internet addiction (Lissak, 2018; Madhav et al., 2017; Twenge \& Campbell, 2018).Prolonged distance learning during COVID-I9 pandemic may have detrimental effects on mental health. As a result, medical students are probably more vulnerable to excessive screen time exposure. To the best of our knowledge, no studies had been conducted among medical students to assess the extent of stress during distance learning and whether screen time could be a strategy to cope with the distress. By knowing this, we can make some recommendation for students related to screen time and mental health to decrease mental health problems among medical students. Hence this paper aims to assess the relationship and compare the level of stress and screen timebefore and after distance learning was initiated.

\section{Methods}

This cross-sectional study was conducted from February to May 2020, at the School of Medicine and Health Sciences, Atma Jaya Catholic University of Indonesia. Ethical approval was obtained from the Ethical Review Committee of School of Medicine and Health Sciences - Atma Jaya Catholic University of Indonesia (No: 04/06/KEP-FKUAJ/2020).

Medical students who had given their consent were eligible for this study. Subjectswere excluded from the study if they meet any of these following: diagnosed with mental disorders or currently consumed psychotropic medications.The minimal sample size required for this study was calculated using the single population proportion formula with $95 \% \mathrm{Cl}, 5 \%$ margin of error, and $50 \%$ of the prevalence of stress (Charan \& Biswas, 20I3). Considering dropout and design error, the sample size was increased up to 215 students.First, to select a sample,proportional stratified sampling was used based on the year of study. As many as 70 subjects from each year batch were recruited and further selected using simple random sampling. Randomization was done using random number generator software, which was adjusted to the names list of students from each year of study. Data collection was done twice with a three-month interval (February and May 
2020). Self-administered questionnaires were distributed online alongside with informedconsent form.

\section{Measurements}

Data measurement was done using questionnaires consisting of three sections: (I) sociodemographics, (2) screen time questionnaire; (3) Medical Students Stressor Questionnaire (MSSQ); and (4) Depression, Anxiety, and Stress Scale-2I (DASS-2I). Length of participants' screen time was measured with built-in Screen Time application for iOs users and Screen Time - Restrain Yourself \& Parental Control version 2.2.I (Iridium Dust Limited) for non-iOs users. Average daily usage was calculated. Collected data was categorized into daily screen time $\geq 7$ hours and $<7$ hours.

MSSQ was used to identify the potential stressors and assess the severity of stress. The tool consisted of 40 items representing six domains of stressors, including academicrelated stressor (ARS), interpersonal and intrapersonal-related stressor (IRS), socialrelated stressor (SRS), teaching and learning-related stressor (TLRS), drive and desirerelated stressor (DRS), and group activities-related stressor (GARS). Participants were asked to rate the severity of stress during the last 7 days in a 5-point-likert scale.The mean scores for each domain were calculated, which ranged between 0-4. A mean score of 0I.00 indicated mild stress, I.0I-2.00 indicated moderate stress, 2.01-3.00 indicated high stress, and 3.0I-4.00 indicated severe stress (Yusoff et al., 20l0). The stress level was later recategorized as normal (mild and moderate stress) and abnormal (high and severe stress).Pearson product moment validity test showed a statistically significant $(P<0.05)$ item-total correlation ranging from 0.39 to 0.76 confirming the good discrimination of each question and the suitability of MSSQ for measuring and obtaining data from respondents in this study. Cronbach's Alpha reliability test also showed significance value more than 0.90 confirming the internal consistency of MSSQ when used repeatedly.Validation of this instrument was also done on the medical student across study year and across medical schools in various countries which was acceptable on content, response process, internal 
structure, relations to other variables, and consequences of its score (Yusoff, 20II, 20I3, 2017).

DASS-2 I was used to measure emotional distress in general consisting of difficulty relaxing, nervous arousal, and being easily upset/agitated, irritable/over-reactive, and impatient. Stress scale contained 7 items in which participants were asked to rate how frequent they experienced each state over the last 7 days in a 4-point-likert scale with a maximum score of 42. A score of 0-14 indicated normal, I5-18 indicated mild stress, 19-25 indicated moderate stress, 26-33 indicated severe stress, and 28-42 indicated extremely severe stress. Pearson product moment validity test showed a statistically significant $(P<0.05)$ item-total correlation for stress scale (item no. I,6,8, I I, I 2, I4, I8) ranging from 0.44 to 0.79 confirming the good discrimination of each question and the suitability of DASS-2I for measuring and obtaining distress data from respondents in this study. Cronbach's Alpha reliability test also showed significance value more than 0.90 confirming the internal consistency of DASS-2I when used repeatedly (Supplementary Figure 2).Validity and reliability of this instrument were acceptable and further confirmed in a worldwide study using individuals with various races (Lovibond \& Lovibond, 1995; Norton, 2007).

\section{Data analysis}

Data were analyzed using Stata Statistical Software: Release 12 (201I) (Stata Statistical Software: Release 12, 2011). Distribution of data was assessed by using Shapiro Wilk normality test. Depends on the result, either dependent sample $T$-test or Wilcoxon signedrank test would be used to analyze whether there was significant differences of level of stress and screen time before and after distance learning was executed. Bivariate analysis using Chi-square andKendall's rank correlation was also done to assess the association between the level of stress and duration of screen time. Statistical significance was accepted at $P<0.05$. 


\section{Results}

Two hundred fifteen students were selected for this study. The response rate during the first survey was $100.0 \%$. However, during the second survey, only 214 students participated and completed the questionnaire, giving an overall response rate of $99.5 \%$. One person was excluded because he was absent throughout the second survey. Then, 7 out of 214 students were further excluded, for they had a history of mental disorders or consuming psychotropic medications. The final sample used for this study was 207 respondents.

Age of 207 respondents ranged from 16 to 22 years (Mean:19.22 \pm 1.03 ). The majority of respondents were female $(69.57 \%)$ and $3^{\text {rd }}$-year medical students(34.78\%). Concerning ethnicity and religion, most of the respondents were Chinese (73.43\%) and Catholic (39.61\%).The prevalence of distress among medical students was $25.61 \%$ and $27.06 \%$ before and after distance learning was executed, respectively. The later was higher, although it was not statistically significant $(P=0.15 \mid 4)$. As shown in Table I, students aged 19 years old and above were more likely to experience distress compared to youngerstudents, even though the difference was not statistically significant $(P=0.057$, $P=0.490)$. Distress was more prominent among female compared to male students in both conditions, but it was not statistically significant $(P=0.5 \mid 8, P=0.237)$. Before distance learning was implemented, the highest prevalence of distress was observed among $I^{\text {st }}$ year medical students $(32.81 \%)$. On the contrary, $3^{\text {rd }}$ year medical students showed the highest level of distress after distance learning was executed (27.78\%), even though the difference was not statistically significant in both conditions $(P=0.204, P=0.920)$. Neither ethnicity $(P=0.72 I, P=0.520)$ nor religion $(P=0.570, P=0.62 I)$ has significant association with distress. 
Table I.

Association between Stress and Sociodemographic Variables among Medical Students.

\begin{tabular}{|c|c|c|c|c|c|c|c|}
\hline \multirow{3}{*}{$\begin{array}{c}\text { Sociodemographic } \\
\text { Variables }\end{array}$} & \multirow{3}{*}{$\begin{array}{l}\text { Total, N } \\
(\%)\end{array}$} & \multicolumn{6}{|c|}{ Distress } \\
\hline & & \multicolumn{3}{|c|}{$\begin{array}{l}\text { Before Distance Learning } \\
\text { (February) }\end{array}$} & \multicolumn{3}{|c|}{$\begin{array}{l}\text { After Distance Learning } \\
\text { (May) }\end{array}$} \\
\hline & & $\begin{array}{c}\text { Yes } \\
(n=53) \\
N(\%)\end{array}$ & $\begin{array}{c}\text { No } \\
(n=154) \\
N(\%)\end{array}$ & $\begin{array}{c}P \\
\text { value }\end{array}$ & $\begin{array}{c}\text { Yes } \\
(n=54) \\
N(\%)\end{array}$ & $\begin{array}{c}\text { No } \\
(n=153) \\
N(\%)\end{array}$ & $\begin{array}{c}P \\
\text { value }\end{array}$ \\
\hline \multicolumn{8}{|l|}{ Age } \\
\hline $16-18$ & $50(24.15)$ & $\begin{array}{l}12 \\
(24.00)\end{array}$ & $38(76.00)$ & 0.057 & $\begin{array}{l}10 \\
(20.00)\end{array}$ & $40(80.00)$ & 0.490 \\
\hline 19 & 71 (34.30) & $\begin{array}{l}25 \\
(35.21)\end{array}$ & $46(64.79)$ & & $\begin{array}{l}21 \\
(29.58)\end{array}$ & $50(70.42)$ & \\
\hline $20-22$ & $86(4 I .55)$ & $\begin{array}{l}16 \\
(18.60)\end{array}$ & $70(81.40)$ & & $\begin{array}{l}23 \\
(26.74)\end{array}$ & $63(73.26)$ & \\
\hline \multicolumn{8}{|l|}{ Gender } \\
\hline Male & $63(30.43)$ & $\begin{array}{l}18 \\
(28.57)\end{array}$ & 45 (7I.43) & 0.518 & $\begin{array}{l}13 \\
(20.63)\end{array}$ & $50(79.37)$ & 0.237 \\
\hline Female & $\begin{array}{l}144 \\
(69.57)\end{array}$ & $\begin{array}{l}35 \\
(24.31)\end{array}$ & $\begin{array}{l}109 \\
(75.69)\end{array}$ & & $\begin{array}{l}41 \\
(28.47)\end{array}$ & $\begin{array}{l}103 \\
(71.53)\end{array}$ & \\
\hline \multicolumn{8}{|l|}{ Academic Year } \\
\hline $1^{\text {st }}$ Year & $64(30.92)$ & $\begin{array}{l}21 \\
(32.8 I)\end{array}$ & $43(67.19)$ & 0.204 & $\begin{array}{l}16 \\
(25.00)\end{array}$ & $48(75.00)$ & 0.920 \\
\hline $2^{\text {nd }}$ Year & 71 (34.30) & $\begin{array}{l}18 \\
(25.35)\end{array}$ & $53(74.65)$ & & $\begin{array}{l}18 \\
(25.35)\end{array}$ & $53(74.65)$ & \\
\hline $3^{\text {rd }}$ Year & 72 (34.78) & $\begin{array}{l}14 \\
(19.44)\end{array}$ & $58(80.56)$ & & $\begin{array}{l}20 \\
(27.78)\end{array}$ & $52(72.22)$ & \\
\hline \multicolumn{8}{|l|}{ Ethnicity } \\
\hline $\begin{array}{l}\text { Chinese } \\
\text { Javanese }\end{array}$ & $\begin{array}{l}152 \\
(73.43) \\
26(12.56)\end{array}$ & $\begin{array}{l}40 \\
(26.32) \\
5(19.23)\end{array}$ & $\begin{array}{l}112 \\
(73.68) \\
21(80.77)\end{array}$ & 0.721 & $\begin{array}{l}37 \\
(24.34) \\
7(26.92)\end{array}$ & $\begin{array}{l}115 \\
(75.66) \\
19(73.08)\end{array}$ & 0.520 \\
\hline Others & $29(14.01)$ & 8 (27.59) & $2 I(72.4 I)$ & & $\begin{array}{l}10 \\
(34.48)\end{array}$ & $19(65.52)$ & \\
\hline \multicolumn{8}{|l|}{ Religion } \\
\hline Catholic & $82(39.61)$ & $\begin{array}{l}24 \\
(29.27)\end{array}$ & $58(70.73)$ & 0.570 & $\begin{array}{l}22 \\
(26.83)\end{array}$ & $60(73.17)$ & 0.621 \\
\hline Christian & 69 (33.33) & $\begin{array}{l}17 \\
(24.64)\end{array}$ & $52(75.36)$ & & $\begin{array}{l}20 \\
(28.99)\end{array}$ & 49 (7I.0I) & \\
\hline Others & $56(27.05)$ & $\begin{array}{l}12 \\
(21.43)\end{array}$ & $44(78.57)$ & & $\begin{array}{l}12 \\
(21.43)\end{array}$ & $44(78.57)$ & \\
\hline
\end{tabular}

Note: Statistical significance indicated in bold.

Before distance learning was implemented, most students (49.28\%) considered ARS as the source of high-to-severe stress in medical schools. SRS (33.33\%) and IRS (31.40\%) were the second and third causes of stress among medical students, respectively. Based on the mean score of each domain, ARS was the source of high stress $(2.00 \pm 0.69)$, followed by

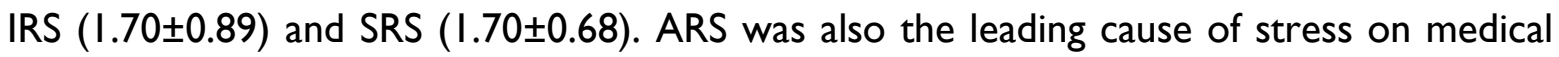


students after distance learning was executed. It is reported that I3 I out of 207 students (63.29\%) had high-to-severe academic-related stress levels. The second and third leading cause of stress reported was IRS (42.03\%) and TLRS (31.88\%), respectively. According to the mean score of each domain,ARS remained the main source of high stress $(2.21 \pm 0.75)$,

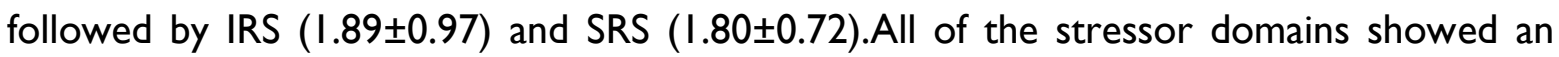
increase in stress levelafter distance learning was implemented (Table 2). However, only 3 out of 6 stressor domains had a statistically significant change of stress level, which included ARS $(P<0.000 \mathrm{I})$, IRS $(P=0.00 \mathrm{I})$, and SRS $(P=0.026 \mathrm{I})$.

Before distance learning was executed, the proportion of students with average daily screen time $\geq 7$ hours was $51.21 \%$, with a mean score of $7.34(S D=2.55)$. There was an increase in the number of students with screen time $\geq 7$ hours per day after the implementation of distance learning, reaching as many as 132 out of 207 students (63.77\%). The mean score of the daily screen time of the second survey was 7.9I (SD=2.87). The rise of average daily screen time during the second survey was statistically significant compared to the first survey $(P=0.0022)$.

Kendall's tau-b correlation was run to assess the relationship between stress level and screen time in medical students. Even though no significant correlation between two variables was observed before distance learning was implemented ( $\tau b=-0.0096, P=0.8624)$, however, there was weak, positive correlation between stress level and screen time after distance learning was executed, which was statistically significant ( $\tau b=0.1186$, $P=0.03$ |3). Chi-square analysis was run to determine the association between various stressors and screen time (Table 3). Before distance learning was implemented, most students with the high-to-severe level of TLRS, SRS, and DRS had increased screen time. The proportion of distressed-students with average daily screen time $\geq 7$ hours was $52.63 \%$ for TLRS, $52.17 \%$ for SRS, and $56.52 \%$ for DRS. However, the association observed between TLRS, SRS, DRS, and screen time was not statistically significant $(P=0.80 \mathrm{I}$, $P=0.844, P=0.4 I 4$, respectively). 
Table 2.

Sources of Distress among Medical Students.

\begin{tabular}{|c|c|c|c|c|c|}
\hline $\begin{array}{l}\text { Medical Students Stressor } \\
\text { Questionnaire (MSSQ) }\end{array}$ & \multicolumn{2}{|c|}{$\begin{array}{l}\text { Before Distance Learning } \\
\text { (February) }\end{array}$} & \multicolumn{2}{|c|}{$\begin{array}{l}\text { After Distance Learning } \\
\text { (May) }\end{array}$} & Pvalue \\
\hline \multicolumn{6}{|l|}{ ARS } \\
\hline Mild & $16(7.73)$ & $2.00 \pm 0.69$ & $13(6.28)$ & $2.21 \pm 0.75$ & $0.0000^{*}$ \\
\hline Moderate & $89(43.00)$ & & $63(30.43)$ & & \\
\hline High & $87(42.03)$ & & $108(52.17)$ & & \\
\hline Severe & $15(7.25)$ & & 23 (1I.1I) & & \\
\hline \multicolumn{6}{|l|}{ IRS } \\
\hline Mild & $52(25.12)$ & $1.70 \pm 0.89$ & $48(23.19)$ & $1.89 \pm 0.97$ & $0.0014^{*}$ \\
\hline Moderate & $90(43.48)$ & & $72(34.78)$ & & \\
\hline High & $50(24.15)$ & & $63(30.43)$ & & \\
\hline Severe & $15(7.25)$ & & 24 (II.59) & & \\
\hline \multicolumn{6}{|l|}{ TLRS } \\
\hline Mild & $59(28.50)$ & $1.61 \pm 0.78$ & $45(21.74)$ & $1.67 \pm 0.78$ & $0.2086^{\dagger}$ \\
\hline Moderate & 91 (43.96) & & $96(46.38)$ & & \\
\hline High & $51(24.64)$ & & $57(27.54)$ & & \\
\hline Severe & $6(2.90)$ & & $9(4.35)$ & & \\
\hline \multicolumn{6}{|l|}{ SRS } \\
\hline Mild & $41(19.81)$ & $1.70 \pm 0.68$ & $36(17.39)$ & $1.80 \pm 0.72$ & $0.026 \mathrm{I}^{\dagger}$ \\
\hline Moderate & $97(46.86)$ & & $108(52.17)$ & & \\
\hline High & $66(31.88)$ & & $54(26.09)$ & & \\
\hline Severe & $3(1.45)$ & & $9(4.35)$ & & \\
\hline \multicolumn{6}{|l|}{ DRS } \\
\hline Mild & $87(42.03)$ & $1.47 \pm 0.94$ & $82(39.6 I)$ & $1.48 \pm 0.93$ & $0.5363^{*}$ \\
\hline Moderate & $74(35.75)$ & & $79(38.16)$ & & \\
\hline High & $35(16.91)$ & & 36 (17.39) & & \\
\hline Severe & II (5.3I) & & $10(4.83)$ & & \\
\hline \multicolumn{6}{|l|}{ GARS } \\
\hline Mild & 6I (29.47) & $1.66 \pm 0.84$ & 49 (23.67) & $1.74 \pm 0.86$ & $0.1292^{\dagger}$ \\
\hline Moderate & $86(41.55)$ & & $96(46.38)$ & & \\
\hline High & $49(23.67)$ & & 47 (22.7I) & & \\
\hline Severe & $1 \mathrm{I}(5.3 \mathrm{I})$ & & $15(7.25)$ & & \\
\hline
\end{tabular}

Abbreviation: ARS: Academic-related Stressor; DRS: Drive and Desire-related Stressor;GARS: Group Activities-related Stressor; IRS: Interpersonal and Intrapersonal-related Stressor; SRS: Social-related Stressor; TLRS: Teaching and Learningrelated Stressor; Note: * Wilcoxon sign-ranked test, $\dagger$ Dependent $T$ test; Statistical significance indicated in bold

Other stressor domains, such as ARS, IRS, and GARS, showed a relatively lower or similar proportion of distressed- students with screen time $\geq 7$ and $<7$ hours per day. Also, no significant association was observed between these stressors domains and screen time $(P=0.732, P=0.494, P=0.404$, respectively). All of the stressors domains showed an increased number of distressed-students with daily screen time $\geq 7$ hours after distance learning was executed. Increased screen time was observed among students with high-tosevere level stress caused by ARS (6I.83\%), IRS (59.77\%), TLRS (63.64\%), SRS (57.14\%), 
DRS (65.22\%), and GARS (69.25\%). However, this high screen time level does not show statistically significant association with the stress occurring among students $(P=0.447$, $P=0.308, P=0.978, P=0.190, P=0.817, P=0.274$, respectively).

Table 3.

Association between Various Stressors and Screen Time among Medical Students.

\begin{tabular}{|c|c|c|c|c|c|c|}
\hline \multirow[b]{3}{*}{ Distress } & \multicolumn{6}{|c|}{ Screen Time } \\
\hline & \multicolumn{3}{|c|}{ Before Distance Learning (February) } & \multicolumn{2}{|c|}{ After Distance Learning (May) } & \multirow[b]{2}{*}{$p$ value } \\
\hline & $\begin{array}{l}\geq 7 \text { hours/day } \\
N(\%)\end{array}$ & $\begin{array}{l}<7 \text { hours/day } \\
N(\%)\end{array}$ & pvalue & $\begin{array}{l}\geq 7 \text { hours/day } \\
N(\%)\end{array}$ & $\begin{array}{l}<7 \text { hours/day } \\
N(\%)\end{array}$ & \\
\hline \multicolumn{7}{|l|}{ ARS } \\
\hline Yes & $51(50.00)$ & $51(50.00)$ & 0.732 & $81(6 \mid .83)$ & $50(38.17)$ & 0.447 \\
\hline No & $55(52.38)$ & $50(47.62)$ & & $5 I(67.1 I)$ & 25 (32.89) & \\
\hline \multicolumn{7}{|l|}{ IRS } \\
\hline Yes & $31(47.69)$ & $34(52.31)$ & 0.494 & $52(59.77)$ & $35(40.23)$ & 0.308 \\
\hline No & $75(52.82)$ & $67(47.18)$ & & $80(66.67)$ & $40(33.33)$ & \\
\hline \multicolumn{7}{|l|}{ TLRS } \\
\hline Yes & $30(52.63)$ & $27(47.37)$ & 0.801 & $42(63.64)$ & $24(36.36)$ & 0.978 \\
\hline No & $76(50.67)$ & $74(49.33)$ & & $90(63.83)$ & $5 I(36.17)$ & \\
\hline \multicolumn{7}{|l|}{ SRS } \\
\hline Yes & $36(52.17)$ & $33(47.83)$ & 0.844 & $36(57.14)$ & $27(42.86)$ & 0.190 \\
\hline No & $70(50.72)$ & 68 (49.28) & & $96(66.67)$ & $48(33.33)$ & \\
\hline \multicolumn{7}{|l|}{ DRS } \\
\hline Yes & $26(56.52)$ & $20(43.48)$ & $0.4 \mid 4$ & $30(65.22)$ & $16(34.78)$ & 0.817 \\
\hline No & $80(49.69)$ & $8 \mathrm{I}(50.3 \mathrm{I})$ & & $102(63.35)$ & $59(36.65)$ & \\
\hline \multicolumn{7}{|l|}{ GARS } \\
\hline Yes & $28(46.67)$ & $32(53.33)$ & 0.404 & 43 (69.35) & $19(30.65)$ & 0.274 \\
\hline No & 78 (53.06) & 69 (49.94) & & 89 (6I.38) & $56(38.62)$ & \\
\hline
\end{tabular}

Abbreviation: ARS: Academic-related Stressor; DRS: Drive and Desire-related Stressor;GARS: Group Activities-related Stressor; IRS: Interpersonal and Intrapersonal-related Stressor; SRS: Social-related Stressor; TLRS: Teaching and Learning-related Stressor.

\section{Discussion}

The prevalence of mental distress was already high among medical students, ranging from $20 \%$ to $52.4 \%$ (Melaku et al., 2015; Nivetha M. et al., 2018). In the present study, the prevalence of distress among medical students was $25.61 \%$ and $27.06 \%$ before and after distance learning was executed, respectively. Another study by Hill et al. (2018) showed as many as $68.6 \%$ of medical students had significant but manageable distress, while $11.2 \%$ 
experienced severe and debilitating distress. The variability in the distress level might be due to differences in curricula, teaching and learning facilities, qualification of lecturers, and level of care given to the students. Other possible reasons were differences in college environment, regional socio-cultural factors, and diagnostic instruments.

Gender was not related to distress. Previous studies had showed similar results (Melaku et al., 2015; Mudor \& Mudor, 20I5; Nivetha. et al., 20I8), except in one study by Chen et al. (20/3).Our study also showed that age was not associated to distress level and in accordance with a study by Melaku et al. (2015), even thoughthe present study produced similar results in which older students were more likely to experience distress (Nivetha M. et al., 2018). Before distance learning was initiated, the prevalence of distress was decreasing as the year of study increased, in accordance with a study by Melaku et al. (20I5). This might be due to gradual adjustment to the learning environment, in which first year medical students had yet to adapt with the medical training they currently receiving, while senior students might have develop skills and strategies to manage their medical education. However, after distance learning was executed, final year of pre-clinical students showed the highest prevalence of distress. Chen et al. (2013) showed that fifth year medical students had the highest level of distress. A possible explanation was that senior students had entered transition phase from pre-clinical to clinical clerkshipand had to prepare for objective structured clinical assessment (OSCA). COVID-I9 pandemic had disrupted students getting adequate on-hands basic practical skills for the upcoming clerkship which might contribute to higher level of distress in final year pre-clinical students. However, this study did not show significant association between academic year and distress level. Similar to previous studies, ethnicity andreligion were not associated with distress level (Melaku, et al., 20I5; Nivetha, et al., 20I8).

ARS was the primary cause of high-to-severe stress among medical students before and after distance learning was executed (49.28\% and 63.29\%, respectively). A similar survey by Nivetha et al. (2018) also showed that $40.9 \%$ of students considered ARS as the source of high stress. Another study by Melaku et al. (2015) found that $60.3 \%$ of students had a highto-severe level of stress caused by ARS.The mean score of ARS in this study was $2.00 \pm 0.69$ initially and $2.21 \pm 0.75$ in three-month after distance learning was executed. The finding was 
similar to a previous studywhich showed a mean score of $2.19 \pm 0.64$ for ARS (Mudor \& Mudor, 20I5). Another studyby Patil et al. (20I7) hadshowed a mean score of $I .6 I \pm 0.88$ for ARS. These findings were related to the facts that medical students might be pressurized because of the overwhelming amount of materials to be mastered, complexity of the syllabus, frequent examinations, unnecessary workloads, low academic perfomance andcompetitive learning environment (Hill et al., 20I8; Yusoff et al., 20I7).

In general, the level of distress before and after the implementation of distance learning were similar. To the best of our knowledge, no study had been conducted in medical students to evaluate the impact of distance learning to psychological distress. However, a study with a general population in China also showed similar levels of distress when the new cases of COVID-19 rapidly increased. Yet, this study supported the fact that prolonged social quarantine had adverse impacts on mental health, especially in the 1221.4-year-old group which was primarily affected by extended school closure, requiring online education assistance and uncertainty about examinations and matriculation arrangements (Wang et al., 2020). The significant rise of stress level before and after the initiation of distancelearning were only observed in stress caused by ARS, IRS, and SRS. Increased in ARS was probably due to students' difficulty understanding the lessons through online classes, abundant assessments, and lacking medical skill practice (Sahu, 2020). Increased in IRS and SRS might be associated with the change of students' learning environment from a standard classroom to online learning at home. Being socially-confined, some students report that they struggle with loneliness, frustration, and boredom. They are also easily distracted and lose motivation to work (Venkatesh \& Edirappuli, 2020).

This study also showed that the proportion of students with daily screen time $\geq 7$ hours was $51.21 \%$ in the early phase and $63.77 \%$ in three months after distance learning was initiated. This number was higher than the previous study done by Kleppang et al. (2019)in which the proportion of adolescents aged 15-16 with sedentary screen time $\geq 6$ hours per day was $32 \%$. Another studyreported the proportion of adults aged 20 and above with daily screen time $>6$ hours was $14.75 \%$ (Madhav et al., 2017). Nonetheless, the average daily screen time in this study was 7.34 and 7.91 hours before and after the execution of distancelearning, respectively. This result was in accordance with a survey in 2019 by 
Common Sense Media which revealed that the average daily screen time of adolescents aged 13-18 years old was 7 hours 22 minutes ("The Common Sense Census", 2020). The duration of daily screen time significantly increased in the second survey compared to the first one. This was probably related to the students' using the online learning platform and self-study in the middle of the pandemic, besides screen time for social and entertainment purposes (Sahu, 2020).

It was worth noting that the daily screen time observed among medical students was very high. Dalle et al. (20I5) recommended that screen time should not exceed 2 hours per day for adolescents aged 6-18 years old.Longer screen time was associated with several adverse effects. Individuals with daily screen time $>2-4$ hours were associated with obesity, increased blood pressure, and impaired sleep quality. Moreover, excessive screen time exposure could lead to vision impairement, dizziness, and discomfort in some parts of the body (Lissak, 20I8). To some extent, people with longer screen time were 4.68 times more likely to experience internet addiction (Asut et al., 2019).

Longer screen time was also associated with psychological disorders. In the present study, there was weak, positive correlation between distress and screen time, especially after distance learning was implemented. This finding was in accordance withstudies conducted by $\mathrm{Xu}$ et al. (2019) and Wang et al. (2015) that revealed that a higher level of stress was associated with excessive use of smartphones.Moreover, another study by Kleppang et al. (2019) found that adolescents with screen time $\geq 6$ hours per day were 1.721 times more likely to suffer from psychological distress. The weak correlation could be explained by the possibility of other coping strategies used by the students, such as sleeping, listening to music, dancing, talking with friends/family, self-evaluation, etc (Nivetha, Ahmed, \& Prashantha, 2018). Other possibility includes the fact that some medical students fail to cope with the distress they currently experienced. Medical students are categorized as young adults, which showed the highest percentage of having difficulty in managing their stress (American Psychological Association, 2012). In this study, we group high and severe stress as abnormal, where this high level of stress leads to mental disorder. Mental disorder happens when the coping strategy, to maintain stress, fails. We can assume that the participants that belong to the abnormal stress group already have mental disorder so 
they cannot use their coping strategy, for example increasing their screen time to find salvation, because they do not have anyinterests in pleasant activities.

As far as our knowledge, this was the first study conducted in medical students to evaluate the level of stress and screen time before and after distance learning. Data from this study suggested high level of distress caused by different stressors and daily screen time before and after distance learning was initiated. Our study implied that medical students had risks of experiencing the detrimental impacts of high level of distress and screen time. Healthcare authorities may gain insight on the current mental health status of the students and thus giving appropriate treatment if there is a decline on mental health or impairment in the quality of life. In addition, our study was conducted on the same subjects at threemonth interval hence making the findings more objective and reliable. However, this study has some limitations. Subjects only included medical students enrolled in the School of Medicine and Health Sciences Atma Jaya Catholic University of Indonesia. Thus findings from this study might show differences in a general setting. This study mainly focused on stressors commonly observed in medical studies and did not take into account other potential stressors during social distancing period, such as low knowledge about COVID19, improper precautionary measures, and concerns about other family members getting the disease.

\section{Conclusion}

Academic-related stressor was the leading cause of stress among medical students. More than half of the respondents had daily screen time $\geq 7$ hours. The level of stress and screen time significantly increased in three-month after distance learning was implemented. There was significant correlation between stress and screen time. We could assume that medical students have increased risk of physical and psychological adverse events after excessive stress and screen time exposure. 


\section{Author Contributions}

Conceptualization and Methodology: GM (Ghea Mangkuliguna, M (Mahaputra), VMS (Veronika M. Sidharta), LH (Linawati Hananta); Data Acquisition: GM; Formal Analysis: GM, M, VMS, M; Writing - Original Draft: GM, M; Writing - Review and Editing: M, VMS, LH; Final Approval: GM, M, VMS, LH.

\section{Acknowledgements}

The author would like to thank dr. Yunisa Astiarani, MPH and dr. Laurentius Aswin Pramono, Sp.PD for providing invaluable insights for this article. The author would also like to thank everyonewho had given emotional support throughout the whole process of writing this article.

Declarations of Interest: None

Funding: None

\section{References}

American Psychological Association. (2012). Stress by generations: 2012. https://www.apa.org. Retrieved October 16, 2020, from https://www.apa.org/news/press/releases/stress/20I2/generations

Asut, O., Abuduxike, G., Acar-Vaizoğlu, S., \& Cali, S. (2019). Relationships between screen time, internet addiction and other lifestyle behaviors with obesity among secondary school students in the Turkish Republic of Northern Cyprus. The Turkish Journal of Pediatrics, 6I, 568. https://doi.org/I0.24953/turkjped.2019.04.0I4

Cao, W., Fang, Z., Hou, G., Han, M., Xu, X., Dong, J., \& Zheng, J. (2020). The psychological impact of the COVID-19 epidemic on college students in China. Psychiatry Research, 287, I I2934-I I2934. https://doi.org/ 10.1016/j.psychres.2020.II 2934

Charan, J., \& Biswas, T. (20I3). How to calculate sample size for different study designs in medical research? Indian Journal of Psychological Medicine, 35(2), I21-126. PubMed. https://doi.org/10.4103/0253-7176.116232 
Chen, J. , Wu, Y. , Yi, H. , Li, Z. , Eshita, Y., Qin, P. , Chen, L. and Sun, J. (20I3) The impact of academic stress on medical students attending college in the Inner Mongolia Area of China. Open Journal of Preventive Medicine, 3, 149-154. doi: 10.4236/ojpm.2013.32019

Dalle, J., Mutalib, A. A., Saad, A. L., Ayub, M. N., Wahab, A. W. A., \& Nasralla, A. M. H. (20I5). Usability considerations make digital interactive book potential for inculcating interpersonal skills. Jurnal Teknologi, 77(29), I56-169. https://doi.org// 0.1 I I I3/jt.v77.6837

Hill, M. R., Goicochea, S., \& Merlo, L. J. (20I8). In their own words: Stressors facing medical students in the millennial generation. Medical Education Online, 23(I), I530558. https://doi.org//0.1080/10872981.2018.1530558

Khalili-Mahani, N., Smyrnova, A., \& Kakinami, L. (2019). To each stress its own screen: A cross-sectional survey of the patterns of stress and various screen uses in relation to self-admitted screen addiction. Journal of Medical Internet Research, 2I(4), el I 485. https://doi.org//0.2196/II485

Kleppang, A. L., Thurston, M., Hartz, I., \& Hagquist, C. (2019). Psychological distress among Norwegian adolescents: Changes between $200 \mathrm{I}$ and 2009 and associations with leisure time physical activity and screen-based sedentary behaviour. Scandinavian Journal of Public Health, 47(2), I66-I73. https://doi.org//0.I I 77//4034948I77I6374

Lissak, G. (20/8). Adverse physiological and psychological effects of screen time on children and adolescents: Literature review and case study. Environmental Research, 164, I49-157. https://doi.org/10.1016/j.envres.2018.01.015

Lovibond, S.H. \& Lovibond, P.F. (1995). Manual for the Depression Anxiety Stress Scales (2nd. Ed.). Sydney: Psychology Foundation.

Madhav, K. C., Sherchand, S. P., \& Sherchan, S. (2017). Association between screen time and depression among US adults. Preventive Medicine Reports, 8, 67-7I. PubMed. https://doi.org//0.1016/j.pmedr.2017.08.005

Melaku, L., Mossie, A., \& Negash, A. (2015). Stress among medical students and its association with substance use and academic performance. Journal of Biomedical Education, 2015, 9. https://doi.org//0.1/55/2015//49509

Mudor, N., \& Mudor, A. (2015). Stress among medical students in the deep south of Thailand (No. 2803508; Proceedings of International Academic Conferences). International Institute of Social and Economic Sciences. https://ideas.repec.org/p

Nivetha M., B., Ahmed, M., \&Prashantha, B. (2018). Perceived stress and source of stress among undergraduate medical students of Government Medical College, Mysore. 
International Journal of Community Medicine and Public Health, 5(8). https://dx.doi.org/I0.18203/2394-6040.ijcmph20183090

Norton P. J. (2007). Depression Anxiety and Stress Scales (DASS-2I): psychometric analysis across four racial groups. Anxiety, stress, and coping, 20(3), 253-265. https://doi.org/I0.1080/106/5800701309279

Patil, S. P., Sadhanala, S., Srivastav, M. U., \& BansodeGokhe, S. S. (20I7). Study of stressors among undergraduate medical students of a teaching medical institution. International Journal of Community Medicine and Public Health; Vol 4, No 9 (2017): September 20 I 7. https://doi.org/I0.18203/2394-6040.ijcmph20I73655

Peta sebaran | Gugus tugas percepatan penanganan COVID-19. covid19.go.id. Retrieved May 28, 2020, from https://covid I9.go.id/peta-sebaran

Rose, S. (2020). Medical student education in the time of COVID-19. JAMA. https://doi.org/I0.100I/jama.2020.5227

Sahu, P. (2020). Closure of universities due to coronavirus disease 2019 (COVID-19): Impact on education and mental health of students and academic staff. Cureus, I2(4), e754I-e754I. PubMed. https://doi.org/I0.7759/cureus.754I

Stata Statistical Software: Release 12 (Version 12). (201 I). [computer software]. StataCorp LP.

The Common Sense Census: Media Use by Tweens and Teens, 2019 | Common Sense Media. Retrieved October II, 2020, from https://www.commonsensemedia.org/research

Twenge, J. M., \& Campbell, W. K. (2018). Associations between screen time and lower psychological well-being among children and adolescents: Evidence from a population-based study. Preventive Medicine Reports, 12, 27I-283. PubMed. https://doi.org/10.1016/j.pmedr.2018.10.003

Venkatesh, A., \& Edirappuli, S. (2020). Social distancing in covid-19: What are the mental health implications? BMJ, 369, m/379. https://doi.org/I0.1 I36/bmj.m / 379

Wang, C., Pan, R., Wan, X., Tan, Y., Xu, L., Mclntyre, R. S., Choo, F. N., Tran, B., Ho, R., Sharma, V. K., \& Ho, C. (2020). A longitudinal study on the mental health of general population during the COVID-I9 epidemic in China. Brain, Behavior, and Immunity, 87, 40-48. https://doi.org/I0.1016/j.bbi.2020.04.028

Wang, J.-L., Wang, H.-Z., Gaskin, J., \& Wang, L.-H. (20I5). The role of stress and motivation in problematic smartphone use among college students. Computers in Human Behavior, 53, 181-188. https://doi.org//0.1016/j.chb.2015.07.005 
WHO coronavirus disease (COVID-19) dashboard. Retrieved July 24, 2020, from https://covid I 9.who.int/

Xu, T.-T., Wang, H.-Z., Fonseca, W., Zimmerman, M. A., Rost, D. H., Gaskin, J., \& Wang, J.-L. (2019). The relationship between academic stress and adolescents' problematic smartphone usage. Addiction Research \& Theory, 27(2), 162-169. https://doi.org//0.1080/16066359.20/8.1488967

Yusoff, M. S. B. (20II). A Multicenter Study on Validity of the Medical Student Stressor Questionnaire (MSSQ). International Medical Journal (1994), 18, 14-18.

Yusoff, M. S. B. (20/3). The stability of MSSQ to measure stressors among medical students. International Medical Journal (1994), 20, I-3.

Yusoff, M. S. B. (2017). A systematic review on validity evidence of medical student stressor questionnaire. Education in Medicine Journal, in press. https://doi.org//0.21315/eimj2017.9.I.I.

Yusoff, M. S. B., Fuad, A., \& Yaacob, M. J. (2010). The development and validity of the medical student stressor questionnaire (MSSQ). ASEAN Journal of Psychiatry, II. 


\section{Appendices}

Supplementary Figure I. Validity and Reliabity of Medical Students Stressor Questionnaire (MSSQ). (a) Before Distance Learning (February) and (b) After Distance Learning (May).

Pearson product moment validity test showed a statistically significant $(P<0.05)$ item-total correlation ranging from 0.39 to 0.76 confirming the good discrimination of each question and the suitability of MSSQ for measuring and obtaining data from respondents in this study. Cronbach's Alpha reliability test also showed significance value more than 0.90 confirming the internal consistency of MSSQ when used repeatedly.

(a) Before Distance Learning (February)

\begin{tabular}{|c|c|c|c|c|c|c|c|}
\hline Item & obs & Sign & $\begin{array}{l}\text { tem-test } \\
\text { corr. }\end{array}$ & $\begin{array}{c}\text { item-rest } \\
\text { corr. }\end{array}$ & $\begin{array}{c}\text { interitem } \\
\text { cov. }\end{array}$ & alpha & Label \\
\hline feb_mssq_s $\sim t$ & 207 & + & 0.5660 & 0.5437 & .402471 & 0.9557 & \\
\hline $\operatorname{var} 75$ & 207 & + & 0.6051 & 0.5808 & .3989339 & 0.9555 & \\
\hline $\operatorname{var} 76$ & 207 & + & 0.6745 & 0.6556 & .3985045 & 0.9552 & \\
\hline $\operatorname{var} 77$ & 207 & + & 0.5809 & 0.5545 & .3990458 & 0.9556 & \\
\hline $\operatorname{var} 78$ & 207 & + & 0.5410 & 0.5136 & .4007887 & 0.9558 & \\
\hline $\operatorname{var} 79$ & 207 & + & 0.6054 & 0.5812 & .3989269 & 0.9555 & \\
\hline $\operatorname{var} 80$ & 207 & + & 0.5952 & 0.5690 & .398193 & 0.9555 & \\
\hline $\operatorname{var} 81$ & 207 & + & 0.5642 & 0.5355 & .3986842 & 0.9557 & \\
\hline $\operatorname{var} 82$ & 207 & + & 0.6642 & 0.6416 & .3959685 & 0.9551 & \\
\hline $\operatorname{var} 83$ & 207 & + & 0.6535 & 0.6277 & .3941485 & 0.9552 & \\
\hline $\operatorname{var} 84$ & 207 & + & 0.6029 & 0.5775 & .3982762 & 0.9555 & \\
\hline $\operatorname{var} 85$ & 207 & + & 0.7259 & 0.7067 & .3937901 & 0.9548 & \\
\hline $\operatorname{var} 86$ & 207 & + & 0.6609 & 0.6386 & .3965479 & 0.9552 & \\
\hline $\operatorname{var} 87$ & 207 & + & 0.6723 & 0.6482 & .3939529 & 0.9551 & \\
\hline $\operatorname{var} 88$ & 207 & + & 0.6800 & 0.6547 & .3921959 & 0.9550 & \\
\hline $\operatorname{var} 89$ & 207 & + & 0.6654 & 0.6408 & .3941233 & 0.9551 & \\
\hline $\operatorname{var} 90$ & 207 & + & 0.6595 & 0.6348 & .394553 & 0.9551 & \\
\hline $\operatorname{var} 91$ & 207 & + & 0.5481 & 0.5183 & .3990138 & 0.9558 & \\
\hline $\operatorname{var} 92$ & 207 & + & 0.5894 & 0.5617 & .3976134 & 0.9556 & \\
\hline $\operatorname{var} 93$ & 207 & + & 0.6201 & 0.5952 & .3974456 & 0.9554 & \\
\hline $\operatorname{var} 94$ & 207 & + & 0.6352 & 0.6104 & .3964311 & 0.9553 & \\
\hline $\operatorname{var} 95$ & 207 & + & 0.7160 & 0.6974 & .3954165 & 0.9549 & \\
\hline $\operatorname{var} 96$ & 207 & + & 0.6010 & 0.5767 & .3991926 & 0.9555 & \\
\hline $\operatorname{var} 97$ & 207 & + & 0.5186 & 0.4863 & .3995164 & 0.9560 & \\
\hline $\operatorname{var} 98$ & 207 & + & 0.6219 & 0.5962 & .3967318 & 0.9554 & \\
\hline $\operatorname{var} 99$ & 207 & + & 0.6286 & 0.6008 & .3946795 & 0.9554 & \\
\hline $\operatorname{var} 100$ & 207 & + & 0.5585 & 0.5274 & .3976509 & 0.9558 & \\
\hline $\operatorname{var} 101$ & 207 & + & 0.5963 & 0.5641 & .3942034 & 0.9556 & \\
\hline $\operatorname{var} 102$ & 207 & + & 0.5520 & 0.5189 & .3969578 & 0.9559 & \\
\hline $\operatorname{var} 103$ & 207 & + & 0.6423 & 0.6159 & .3946626 & 0.9553 & \\
\hline $\operatorname{var} 104$ & 207 & + & 0.6112 & 0.5818 & .394887 & 0.9555 & \\
\hline $\operatorname{var} 105$ & 207 & + & 0.6080 & 0.5793 & .3955778 & 0.9555 & \\
\hline $\operatorname{var} 106$ & 207 & + & 0.5274 & 0.4921 & .3974963 & 0.9561 & \\
\hline $\operatorname{var} 107$ & 207 & + & 0.6255 & 0.6008 & .3971921 & 0.9554 & \\
\hline $\operatorname{var} 108$ & 207 & + & 0.6417 & 0.6173 & .3962586 & 0.9553 & \\
\hline $\operatorname{var109}$ & 207 & + & 0.6210 & 0.5928 & .3950028 & 0.9554 & \\
\hline $\operatorname{var} 110$ & 207 & + & 0.6915 & 0.6693 & .3940456 & 0.9550 & \\
\hline $\operatorname{var} 111$ & 207 & + & 0.4287 & 0.3929 & .4029759 & 0.9566 & \\
\hline $\operatorname{var} 112$ & 207 & + & 0.6032 & 0.5762 & .3971337 & 0.9555 & \\
\hline feb_mssq_end & 207 & + & 0.5878 & 0.5564 & .3953951 & 0.9557 & \\
\hline Test scale & & & & & .3968646 & 0.9565 & mean (unstandardized items) \\
\hline
\end{tabular}


(b) After Distance Learning (May)

\begin{tabular}{|c|c|c|c|c|c|c|c|}
\hline Item & Obs & Sign & $\begin{array}{c}\text { item-test } \\
\text { corr. }\end{array}$ & $\begin{array}{c}\text { item-rest } \\
\text { corr. }\end{array}$ & $\begin{array}{c}\text { interitem } \\
\text { cov. }\end{array}$ & alpha & Label \\
\hline may_mssq_s t & 207 & + & 0.6192 & 0.5987 & .478762 & 0.9653 & \\
\hline $\operatorname{var} 115$ & 207 & + & 0.5983 & 0.5760 & .478752 & 0.9654 & \\
\hline $\operatorname{var} 116$ & 207 & + & 0.6822 & 0.6635 & .4757161 & 0.9650 & \\
\hline $\operatorname{var} 117$ & 207 & + & 0.6890 & 0.6698 & .4744884 & 0.9649 & \\
\hline $\operatorname{var} 118$ & 207 & + & 0.6039 & 0.5797 & .4767246 & 0.9653 & \\
\hline $\operatorname{var} 119$ & 207 & + & 0.6762 & 0.6559 & .4744039 & 0.9650 & \\
\hline $\operatorname{var} 120$ & 207 & + & 0.7100 & 0.6908 & .4723957 & 0.9648 & \\
\hline $\operatorname{var} 121$ & 207 & + & 0.6433 & 0.6193 & .4736816 & 0.9652 & \\
\hline $\operatorname{var} 122$ & 207 & + & 0.6745 & 0.6538 & .4741187 & 0.9650 & \\
\hline $\operatorname{var} 123$ & 207 & + & 0.6990 & 0.6788 & .4721887 & 0.9649 & \\
\hline $\operatorname{var} 124$ & 207 & + & 0.7718 & 0.7568 & .4710293 & 0.9646 & \\
\hline $\operatorname{var} 125$ & 207 & + & 0.6621 & 0.6414 & .4752867 & 0.9651 & \\
\hline $\operatorname{var} 126$ & 207 & + & 0.6861 & 0.6663 & .4740298 & 0.9650 & \\
\hline $\operatorname{var} 127$ & 207 & + & 0.7120 & 0.6926 & .4718204 & 0.9648 & \\
\hline $\operatorname{var} 128$ & 207 & + & 0.7327 & 0.7126 & .4685069 & 0.9647 & \\
\hline $\operatorname{var} 129$ & 207 & + & 0.7153 & 0.6964 & .4721373 & 0.9648 & \\
\hline $\operatorname{var} 130$ & 207 & + & 0.6801 & 0.6593 & .4734787 & 0.9650 & \\
\hline $\operatorname{var} 131$ & 207 & + & 0.5728 & 0.5465 & .4773968 & 0.9655 & \\
\hline $\operatorname{var} 132$ & 207 & + & 0.6161 & 0.5937 & .4773626 & 0.9653 & \\
\hline $\operatorname{var} 133$ & 207 & + & 0.6170 & 0.5933 & .4761595 & 0.9653 & \\
\hline $\operatorname{var} 134$ & 207 & + & 0.5819 & 0.5560 & .4770683 & 0.9655 & \\
\hline $\operatorname{var} 135$ & 207 & + & 0.6813 & 0.6618 & .4748588 & 0.9650 & \\
\hline $\operatorname{var} 136$ & 207 & + & 0.6766 & 0.6562 & .4742104 & 0.9650 & \\
\hline $\operatorname{var137}$ & 207 & + & 0.5426 & 0.5121 & .4767197 & 0.9657 & \\
\hline $\operatorname{var} 138$ & 207 & + & 0.6657 & 0.6434 & .4732525 & 0.9651 & \\
\hline $\operatorname{var} 139$ & 207 & + & 0.6634 & 0.6403 & .4726347 & 0.9651 & \\
\hline $\operatorname{var} 140$ & 207 & + & 0.6752 & 0.6513 & .470618 & 0.9650 & \\
\hline $\operatorname{var} 141$ & 207 & + & 0.6319 & 0.6053 & .4723462 & 0.9653 & \\
\hline $\operatorname{var} 142$ & 207 & + & 0.6673 & 0.6427 & .4707251 & 0.9651 & \\
\hline $\operatorname{var} 143$ & 207 & + & 0.7528 & 0.7343 & .4680753 & 0.9646 & \\
\hline $\operatorname{var} 144$ & 207 & + & 0.6677 & 0.6421 & .4696799 & 0.9651 & \\
\hline $\operatorname{var} 145$ & 207 & + & 0.6201 & 0.5929 & .4729128 & 0.9653 & \\
\hline $\operatorname{var} 146$ & 207 & + & 0.4864 & 0.4531 & .478943 & 0.9660 & \\
\hline $\operatorname{var} 147$ & 207 & + & 0.6929 & 0.6750 & .4757228 & 0.9650 & \\
\hline $\operatorname{var} 148$ & 207 & + & 0.7066 & 0.6872 & .4724382 & 0.9649 & \\
\hline $\operatorname{var} 149$ & 207 & + & 0.7093 & 0.6896 & .4718221 & 0.9648 & \\
\hline $\operatorname{var} 150$ & 207 & + & 0.7419 & 0.7245 & .4712853 & 0.9647 & \\
\hline $\operatorname{var} 151$ & 207 & + & 0.4709 & 0.4399 & .4811193 & 0.9660 & \\
\hline $\operatorname{var} 152$ & 207 & + & 0.6225 & 0.5976 & .4746775 & 0.9653 & \\
\hline may_mssq_end & 207 & + & 0.7024 & 0.6801 & .4694002 & 0.9649 & \\
\hline Test scale & & & & & .4739237 & 0.9659 & mean (unstandardized items) \\
\hline
\end{tabular}


Supplementary Figure 2. Validity and Reliabity of Depression, Anxiety, Stress Scale-2I (DASS-2I). (a) Before Distance Learning (February) and (b) After Distance Learning (May).

Pearson product moment validity test showed a statistically significant $(P<0.05)$ item-total correlation for stress scale (item no. $1,6,8,1 \mathrm{I}, 12,14,18$ ) ranging from 0.44 to 0.79 confirming the good discrimination of each question and the suitability of DASS-2I for measuring and obtaining distress data from respondents in this study. Cronbach's Alpha reliability test also showed significance value more than 0.90 confirming the internal consistency of DASS-2I when used repeatedly.

(a) Before Distance Learning (February)

\begin{tabular}{|c|c|c|c|c|c|c|c|}
\hline Item & Obs & Sign & $\begin{array}{c}\text { tem-test } \\
\text { corr. }\end{array}$ & $\begin{array}{c}\text { item-rest } \\
\text { corr. }\end{array}$ & $\begin{array}{c}\text { interitem } \\
\text { cov. }\end{array}$ & alpha & Label \\
\hline feb_dass_s t & 207 & + & 0.7860 & 0.7573 & .2712945 & 0.9421 & \\
\hline $\operatorname{var} 179$ & 207 & + & 0.4075 & 0.3412 & .2876714 & 0.9488 & \\
\hline $\operatorname{var} 180$ & 207 & + & 0.6944 & 0.6606 & .2785281 & 0.9436 & \\
\hline $\operatorname{var} 181$ & 207 & + & 0.6133 & 0.5795 & .2851023 & 0.9448 & \\
\hline $\operatorname{var} 182$ & 207 & + & 0.6506 & 0.5962 & .2716498 & 0.9451 & \\
\hline var183 & 207 & + & 0.6868 & 0.6441 & .2737265 & 0.9438 & \\
\hline $\operatorname{var} 184$ & 207 & + & 0.6581 & 0.6244 & .2818127 & 0.9441 & \\
\hline var185 & 207 & + & 0.8167 & 0.7891 & .2668619 & 0.9414 & \\
\hline $\operatorname{var} 186$ & 207 & + & 0.7779 & 0.7416 & .2656226 & 0.9423 & \\
\hline $\operatorname{var} 187$ & 207 & + & 0.6981 & 0.6616 & .2763492 & 0.9435 & \\
\hline $\operatorname{var} 188$ & 207 & + & 0.7738 & 0.7487 & .2764644 & 0.9425 & \\
\hline $\operatorname{var} 189$ & 207 & + & 0.7623 & 0.7292 & .27078 & 0.9424 & \\
\hline $\operatorname{var} 190$ & 207 & + & 0.7789 & 0.7524 & .2744491 & 0.9423 & \\
\hline var191 & 207 & + & 0.7459 & 0.7137 & .2738713 & 0.9427 & \\
\hline $\operatorname{var} 192$ & 207 & + & 0.7235 & 0.6878 & .2739991 & 0.9431 & \\
\hline $\operatorname{var} 193$ & 207 & + & 0.7208 & 0.6876 & .2761864 & 0.9432 & \\
\hline $\operatorname{var} 194$ & 207 & + & 0.6981 & 0.6620 & .2766592 & 0.9435 & \\
\hline var195 & 207 & + & 0.6098 & 0.5642 & .2797378 & 0.9449 & \\
\hline $\operatorname{var196}$ & 207 & + & 0.6627 & 0.6217 & .2772438 & 0.9441 & \\
\hline $\operatorname{var197}$ & 207 & + & 0.7591 & 0.7286 & .2735521 & 0.9425 & \\
\hline feb_dass_end & 207 & + & 0.6525 & 0.6113 & .2781051 & 0.9442 & \\
\hline Test scale & & & & & .2756985 & 0.9461 & mean (unstandardized items) \\
\hline
\end{tabular}


(b) After Distance Learning (May)

\begin{tabular}{|c|c|c|c|c|c|c|c|}
\hline Item & Obs & Sign & $\begin{array}{l}\text { tem-test } \\
\text { corr. }\end{array}$ & $\begin{array}{l}\text { item-rest } \\
\text { corr. }\end{array}$ & $\begin{array}{c}\text { interitem } \\
\text { cov. }\end{array}$ & alpha & Label \\
\hline may_dass_s t & 207 & + & 0.6052 & 0.5458 & .2046121 & 0.9144 & \\
\hline $\operatorname{var} 155$ & 207 & + & 0.4836 & 0.4095 & .2094379 & 0.9179 & \\
\hline $\operatorname{var} 156$ & 207 & + & 0.7014 & 0.6653 & .206087 & 0.9121 & \\
\hline var157 & 207 & + & 0.4676 & 0.4229 & .216197 & 0.9165 & \\
\hline $\operatorname{var} 158$ & 207 & + & 0.5403 & 0.4754 & .2077189 & 0.9160 & \\
\hline var159 & 207 & + & 0.6744 & 0.6248 & .2022645 & 0.9125 & \\
\hline $\operatorname{var} 160$ & 207 & + & 0.3810 & 0.3236 & .2173698 & 0.9183 & \\
\hline $\operatorname{var} 161$ & 207 & + & 0.6455 & 0.5922 & .2033828 & 0.9132 & \\
\hline $\operatorname{var} 162$ & 207 & + & 0.7166 & 0.6667 & .1978557 & 0.9114 & \\
\hline $\operatorname{var} 163$ & 207 & + & 0.6511 & 0.6081 & .206903 & 0.9130 & \\
\hline var164 & 207 & + & 0.6320 & 0.5881 & .2079165 & 0.9135 & \\
\hline varios & $\angle U I$ & + & 0.0050 & 0.0101 &.$\angle U 43081$ & $0 . y \perp \angle 1$ & \\
\hline $\operatorname{var} 166$ & 207 & + & 0.7656 & 0.7294 & .1995415 & 0.9101 & \\
\hline var167 & 207 & + & 0.6716 & 0.6259 & .2041789 & 0.9125 & \\
\hline $\operatorname{var} 168$ & 207 & + & 0.7175 & 0.6786 & .2032454 & 0.9115 & \\
\hline $\operatorname{var} 169$ & 207 & + & 0.5875 & 0.5380 & .2089099 & 0.9144 & \\
\hline $\operatorname{var} 170$ & 207 & + & 0.6671 & 0.6184 & .2032976 & 0.9126 & \\
\hline var171 & 207 & + & 0.5167 & 0.4413 & .2070385 & 0.9174 & \\
\hline $\operatorname{var} 172$ & 207 & + & 0.6556 & 0.6090 & .2050805 & 0.9129 & \\
\hline $\operatorname{var} 173$ & 207 & + & 0.6847 & 0.6462 & .2062828 & 0.9124 & \\
\hline may_dass_end & 207 & + & 0.5519 & 0.5033 & .2112769 & 0.9151 & \\
\hline Test scale & & & & & .2063317 & 0.9176 & mean (unstandardized items) \\
\hline
\end{tabular}

